\title{
Research on Saturation Detection Circuit for Power MosFET
}

\author{
A. Wang \\ Lanzhou Institute of Physics \\ Lanzhou, China
}

\begin{abstract}
With big projects implementation, such as space station and cargo spacecraft in orbit increasing the dosage of the secondary power supply, the requirement of increasing the for reliability, used in great quantities however on-orbit secondary power supply of power MosFET can only conservative derating use, no effective protection methods. Based on the half bridge topology of power circuit of MosFET possible failure mode analysis put forward a kind of power MosFET saturation detection circuit. Circuit is characterized by low detection threshold lag, shut off the fast response, junction temperature compensation. Refund saturation in this paper, the detection circuit is analyzed and pointed out that the stray inductance of moderate packaging cause impact on short circuit detection threshold.
\end{abstract}

Keyword- a half bridge topology; saturation test; short circuit protection; stray inductance

\section{INTRODUCTION}

All the spacecraft orbiting the busbar distribution using solar panels, the electricity load according to the requirements of power voltage and power, the configuration of various secondary DC - DC converter, converts a bus to the DC voltage required. The present domestic development of the secondary power supply converter internal regardless of topology, all you need to use the power MosFET as electronic switch, realize the power transfer. For the use of power MosFET, can only be in accordance with the relevant derating requirements; reduce the voltage and current stress. For the protection of the power MosFET, but not very good method.

Industry has many solve the logic integrated circuit of IGBT saturation detection, such as mitsubishi M57962AL [1], can according to the inner self protection function to its all kinds of abnormal fast protection. According to this idea, we put forward for power MosFET, also adopts a similar way to achieve rapid protection.

Power MosFET differs from that of IGBT, however, the market solve the IGBT saturation detection logic integrated circuit (IC), cannot be directly used for power MosFETs on-resistance will use, mainly because of the power MosFET is extremely low leakage source on resistance Rds (on), can only produce low leakage conduction voltage source, the IGBT saturation detection logic integrated circuit saturation detection threshold voltage is high, like a collection of emitter turn-on voltage of IGBT in short-circuit cases about $5 \mathrm{~V}$ to $10 \mathrm{~V}$ or higher. Compared with the power MosFET drain-source voltage conduction under the condition of same only a few hundred millivolts.

\author{
W.G. Wang, R. Wu, Q. Zhang \\ Lanzhou Institute of Physics \\ Lanzhou, China
}

There are a few IC, can be used to power MosFET, developed by companies such as IR IR212x [2]. These disadvantages due to the change of components of IC lead to very high testing lag, which makes the precise adjustment current detection threshold is difficult. IR212x circuit design guide [3] is primarily not to consider packaging lead to the influence of induced voltage caused by stray inductance. In low voltage, high current applications these induced voltage affect the corresponding short-circuit detection threshold, the accurate design should be considered in the calculation of the influence of induced voltage.

Another bad effect is power MosFET drain-source on resistance Rds (on) high temperature drift. In the working temperature range with the temperature rising, conduction resistance Rds (on) the basic according to 2 times the left and right sides are raising slope, is about $0.64 \% /{ }^{\circ} \mathrm{C}$. Leading to conduction resistance Rds (on) more temperature, temperature of positive feedback. So back saturation detection circuit to have low detection threshold lag and junction temperature compensation requirements.

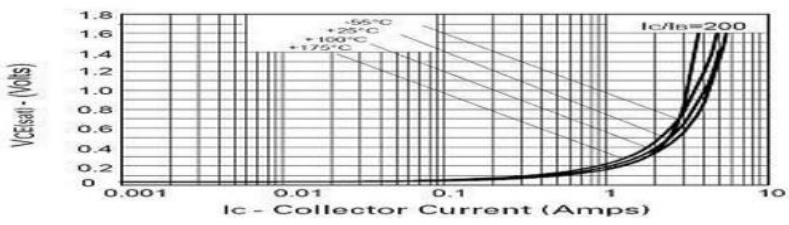

FIGURE I. RDS (ON) CHANGES WITH THE TEMPERATURE CURVE.

Saturation detection circuit of back analysis, this paper mainly discusses the power MosFET low detection threshold lag, shut off the fast response and junction temperature compensation is introduced and the design.

\section{A HALF BRIDGE STRUCTURE IN POWER MOSFET SWITCH}

Figure 2 is a typical traditional power MosFET gate drive circuit. In switched on and off process of power MosFET current and voltage characteristic is shown in figure 3 [4]. Considering all the dotted lines show current path under the influence of stray inductance L sigma theory of voltage characteristic curve. Diagram shows the current and voltage rising and falling time and power MosFET on and off delay time. 


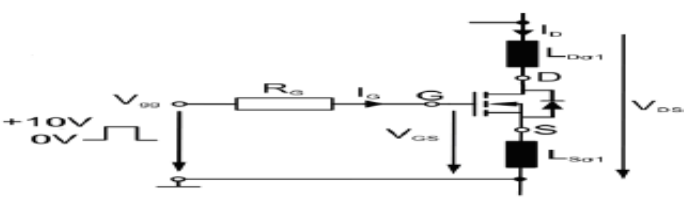

FIGURE II. THE TYPICAL POWER MOSFET GATE DRIVE CIRCUIT IN COMMON USE.

The rise and fall of the current time affected by stray inductance current transmission path is very big. MosFET open process, considering the influence of stray inductance LS sigma 1, current slope and transconductance GFS, input capacitance of power MosFET Ciss and gate threshold voltage Vgs, the relationship between th can approximate to [5] - [6] :

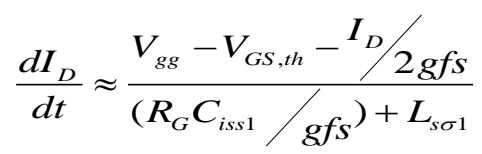

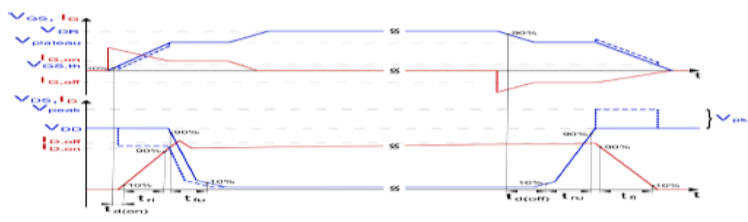

FIGURE III. SWITCH ON AND OFF IN THE PROCESS OF THE MOSFET

(DASHED LINE) AND NOT CONSIDERING (SOLID LINE) THE INFLUENCE OF STRAY INDUCTANCE L $\Sigma$ SIGMA TRANSFORMATION PATH THEORY OF CURRENT AND VOLTAGE CHARACTERISTIC CURVE.

Open process current rise time transfer path caused by the stray inductance are induced voltage in power MosFET Q2 lower voltage stress. This phase voltage decreases:

$$
\mathrm{V}_{\text {ind }}=\mathrm{L} \sigma \times \frac{d i_{D}}{d t}
$$

Shut off process induced voltage caused by stray inductance current fall time is negative, consider to open the turn-off transient process of reverse body diode Q1 overvoltage caused by VFRM peak voltage is as follows:

$$
\mathrm{V}_{\mathrm{pk}}=\mathrm{L} \sigma \times \frac{d i_{D}}{d t}+\mathrm{V}_{F P M}
$$

In short circuit conditions, the stray inductance and current path load inductance current slope is mainly the influence of the parameters. Especially LD $\sigma 1$ and LS $\sigma 1$ serious influence saturation detection performance and response of the circuit. For example, a typical D2PAK package stray inductance $\mathrm{LD} \sigma 1$ and LS $\sigma 1$ sum is about 6-10 $\mathrm{uH}$, but for the short circuit detecting circuit of the threshold value ID,th, had important effect, the sum total of the stray inductance LD $\sigma 1$ and LS $\sigma 1$ under the influence of induced voltage drop can be refund saturation detection circuit is much higher than the reference voltage. Without considering stray inductance, this can lead to much lower than the theoretical value of short circuit detection threshold. In addition, a half-bridge topology sprocket circuit instantaneous possible retreat saturation detection circuit transient fault. In this case, the response time and shut off the current determines the transmission delay time of the refund saturation detection circuit and filtering time constant.

\section{A HALF BRIDGE TOPOLOGY STRUCTURE TYPE OF SHORT CIRCUIT}

Figure 4 shows the two possible short-circuit half bridge topology type, as shown in the literature [7]. Type 1 is load short circuit, such as transformer coil winding short circuit. In this case, the current slope depends on the coil inductance, connecting cable or other circuit inductance. So switch tube has a low current slope.

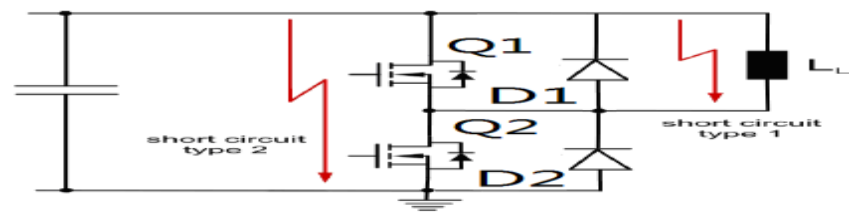

FIGURE IV. A HALF BRIDGE TOPOLOGY STRUCTURE TYPE OF SHORT CIRCUIT.

Assume that controller or switch on and off signals of transmission failure, high-end low Q1 and Q2 half bridge two switches will be an overlap conduction time. Cause a lot of current spikes. The short circuit type 2, common mode short circuit. In this case, due to the very low stray inductance current transmission path, compared with the short circuit type 1 , type of short circuit current slope of 2 will be higher. So short circuit type 2 is more difficult to deal with, because of the need to react quickly withdrew saturation detection circuit.

\section{POWER MOSFET OF SATURATED CONTROL CIRCUIT}

Figure 5 shows the back the principle of saturation detection circuit used in this state, the power MosFET have a very small current through R1 and D1 injected into the power level. Such power MosFET actual drain-source voltage VDS and positive pressure drop VF of the diode D1 through resistor R2, R3 partial pressure measurement. R3 partial pressure on the value set in the reference voltage VREF compare fast. Diode D2 is used in the high and low temperature within a certain temperature compensation.

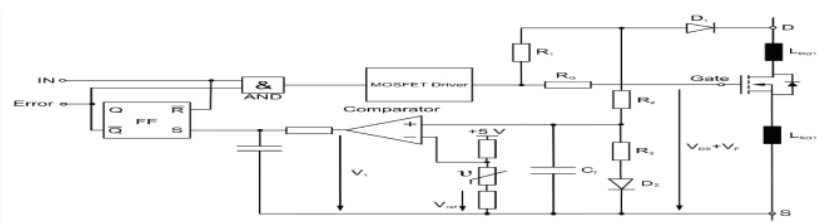

FIGURE V. A SATURATION DETECTION CIRCUIT FOR POWER MOSFET.

If measurement of $\mathrm{VDS}+\mathrm{VF}$ voltage higher than the reference voltage, which means that the failure or MosFET as the output of the comparator output voltage V1 for high level $5 \mathrm{~V}$. In order to reduce saturated reference voltage circuit to VREF is influenced by temperature, voltage reference VREF is affected by power device shell temperature, measured with a thermal resistor. Thermistor resistance decreases with the increase of temperature; this will lead to a reference voltage VREF to rise.

Detected IN power MosFET as time higher drain-source voltage which is exist, the error signal filtering of the comparator takes about a few picosecond time constant, then the RS flip-flop will remain error signals, as time is not can 
make detection circuit, as IN $=0$, the trigger at the next higher level logic input signal arrives IN reset. The input signal is applied to drive IN before, there is no failure is detected, by a logic gate output signal. Keep a low level or drive the input signal. Finally, the control signal is applied to the MosFET drive.

We are concerned about the low latency of all devices, especially the comparator, can be as small as possible. We use of TI company comparator TL3016 [8], transmission delay time of typical value of $7.8 \mathrm{~ns}$. Besides measuring the filter time constant use of VDS + VF also in hundreds of ns or smaller range, the reason for this is in short circuit type 2 quick response fast rise of short circuit current.

\section{SHORT CIRCUIT ANALYSIS}

The proposed saturation detection circuit uses half bridge topology test, as shown in figure 4. In this experiment, drive part of the power provided by the PWM in isolation.

This IR company is used in the experiment of $200 \mathrm{~V}$ power MosFET 2N7219 [9]. Choose the load inductance of $50 \mathrm{uH}$, dc voltage $24 \mathrm{~V}$ (can test under $100 \mathrm{~V}$, but the voltage may cause device damage, do not use analysis). In theory of short circuit detection threshold of 15A. Different junction temperature of short circuit detection threshold analysis is based on the installed on temperature control heating plate. In the process of power MosFET shutoff no short circuit occurs, the current fall time comparator output signal is set to $5 \mathrm{~V}$. This is on the transmission path induced voltage caused by the stray inductance. In order to avoid bad command driven stage, the trigger in the cut-off time and power MosFET can shut off process can't make fault signal.

\section{A. Short circuit Type 1}

Because of the reason of the load line, about $3 \mathrm{uH}$ remaining stray inductance, relatively high, short circuit current slope is relatively low. In leakage when the source current is $14.7 \mathrm{~A}$ saturation detection circuit back to the error signal, power MosFET shut off after A propagation delay about 30 ns. The actual short circuit detection threshold 15 a relatively lower than the theoretical value. Is mainly caused by induction voltage, under this kind of short circuit type set induced voltage in the range of 50-150 mV. Thermistor temperature compensation is dependent on the state power MosFET drive drain-source voltage, because the on-state drain-source resistance RDS is more sensitive to temperature, under their respective shell temperature curve of intersection is slightly different.

TABLE I. SHORT CIRCUIT TYPE 1 UNDER DIFFERENT CASE TEMPERATURE LOAD SATURATION DETECTION CIRCUIT FOR TEMPERATURE COMPENSATION SHORT CIRCUIT DETECTION THRESHOLD MEASUREMENT.

\begin{tabular}{|l|l|l|}
\hline$T C$ & $\begin{array}{l}\text { ID,th,meas } \\
\text { with temperature compensation }\end{array}$ & $\begin{array}{l}\text { ID,th,meas } \\
\text { without temperature } \\
\text { compensation }\end{array}$ \\
\hline $25^{\circ} \mathrm{C}$ & $14.4 \mathrm{~A}$ & $14.1 \mathrm{~A}$ \\
\hline $50^{\circ} \mathrm{C}$ & $14.5 \mathrm{~A}$ & $13.6 \mathrm{~A}$ \\
\hline $75^{\circ} \mathrm{C}$ & $14.8 \mathrm{~A}$ & $12.5 \mathrm{~A}$ \\
\hline $100^{\circ} \mathrm{C}$ & $14.7 \mathrm{~A}$ & $11.2 \mathrm{~A}$ \\
\hline $125^{\circ} \mathrm{C}$ & $14.3 \mathrm{~A}$ & $10.1 \mathrm{~A}$ \\
\hline
\end{tabular}

Under different case temperature are listed in table 1 for temperature compensation of power MosFET short circuit detection threshold measurement. You can see that the short circuit detection threshold under different case temperature change with temperature compensation is very small; on the contrary, without the change of temperature compensation is very large.

Compared to the load side short circuit, switch coil short circuit directly lead to faster current rising slope. Due to the short wire stray inductance is small. Short circuit inductance of the current path for this experiment set to about $100 \mathrm{NH}$. When open the comparator output voltage is set to $0 \mathrm{~V}$ again. After a short time, high saturation detection circuit back to the drain-source voltage. Caused by stray inductance MOSFET shell induced voltage drop, short circuit on the converter end when short circuit detection threshold than when short circuit at the load end short circuit detection threshold is low. Closed transfer delay tspd and is the same as before.

\section{B. Short Circuit Type 2}

Short circuit type 2 short circuit type 1 will result in faster compared current rise. Current rising stage encapsulation inductance $\mathrm{LD} \sigma 1$ and $\mathrm{LS} \sigma 1$ general induction voltage drop to about $3 \mathrm{~V}$. Due to encapsulate the whole transformation path inductance (LD $\sigma 1+\mathrm{LS} \sigma 1)$ and the influence of stray inductance, input comparator drain-source electrode measured voltage VDS, meas is still higher than the reference voltage of the whole process of open VREF. Delay for a period of time (ns) after boot, appear fault signal V1 comparator output filter, the signal before the open and shut off the power MosFET on RS trigger.

In table II lists the short circuit test under different shell temperature threshold and short circuit fault current. You can see that the short circuit detection threshold in essence is not affected by temperature. As mentioned in section 2, a short circuit detection threshold is only affected by comparator input filter time constant.

TABLE II. WITHOUT TEMPERATURE COMPENSATION WHEN SHORT CIRCUIT UNDER DIFFERENT CASE TEMPERATURE TYPE 2 TO SATURATION DETECTION CIRCUIT SHORT CIRCUIT DETECTION THRESHOLD VALUE ID, TH, MEAS AND SHORT-CIRCUIT SHUT OFF THE CURRENT MEASUREMENT.

\begin{tabular}{|l|l|l|}
\hline$T C$ & ID,th,meas & ID,sc (off) \\
\hline $25^{\circ} \mathrm{C}$ & $15 \mathrm{~A}$ & $16.1 \mathrm{~A}$ \\
\hline $50^{\circ} \mathrm{C}$ & $15 \mathrm{~A}$ & $16.1 \mathrm{~A}$ \\
\hline $75^{\circ} \mathrm{C}$ & $14.8 \mathrm{~A}$ & $16 \mathrm{~A}$ \\
\hline $100^{\circ} \mathrm{C}$ & $14.6 \mathrm{~A}$ & $15.9 \mathrm{~A}$ \\
\hline $125^{\circ} \mathrm{C}$ & $14.5 \mathrm{~A}$ & $15.8 \mathrm{~A}$ \\
\hline
\end{tabular}

\section{CONCLUSION}

This paper puts forward and analyzes the use of junction temperature under different shell temperature compensation of power MosFET of saturation detection circuit. Describe current transmission path in the process of the switch power MosFET switch behaviors and the influence of stray inductance. Then analyzed the MosFET encapsulation inductance effects on short circuit detection threshold. Presents a half bridge topology may be two types of short circuit. Further details the low voltage power MosFET retreat saturation of the circuit design, recommend parameters is 
given. Analyzes the different types and different case temperature, short circuit, saturation detection circuit back very fast response and short circuit detection threshold small changes. In the event of short circuit type 1, short circuit detection threshold depends on the short-circuit load of the case temperature, in the event of short circuit type 2, mainly depends on short circuit detection threshold filtering time constant.

\section{REFERENCE}

[1] M57962AL Hybrid IC for driving IGBT modules Datasheet, ISAHAYA.

[2] I. Rectifier, Current Sensing Single Channel Driver, IR212X, Datasheet. International Recited.

[3] I. Rectifier, Using The Current Sensing IR212X Gate Drive ICs, Application Note AN-1014. International Rectifier.

[4] B. Wittig and F. Fuchs, "Analysis and improvement of the switching behaviour of low voltage power mosfets with high current ratings under hard switching conditions." Bari: IEEE International Symposium on Industrial Electronics, 2010.

[5] A. Galluzzo, M. Melito, G. Belverde, "Switching characteristic improvement of modern gate controlled devices." Brighton: Fifth European Conference on Power Electronics and Applications, 1993.

[6] S. Musumeci, A. Raciti, A. Testa, "Switching-behavior improvement of insulated gate-controlled devices," IEEE Transactions on Power Electronics, vol. 12, no. 4, 1997.

[7] J. Lutz, R. Dbler, J. Mari, and M. Menzel, "Short circuit iii in high power igbts." Barcelona: 13th European Conference on Power Electronics and Applications, 2009.

[8] Texas. Instruments, TL3016, Datasheet. TL3016

[9] I. Rectifier, JANTXV POWER MOSFET 2N7219 PbF, Datasheet. In-ternational Rectifier. 